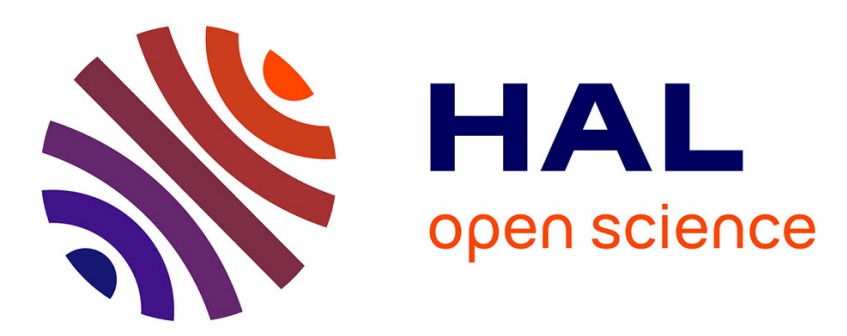

\title{
Synthesis of zeolite SSZ-24 using a catalytic amount of SSZ-13 seeds
}

Lingxue Tang, Kok-Giap Haw, Ping He, Qianrong Fang, Shilun Qiu, Valentin Valtchev

\section{> To cite this version:}

Lingxue Tang, Kok-Giap Haw, Ping He, Qianrong Fang, Shilun Qiu, et al.. Synthesis of zeolite SSZ-24 using a catalytic amount of SSZ-13 seeds. Inorganic Chemistry Frontiers, 2019, 6 (11), pp.3097-3103. 10.1039/C9QI00971J . hal-02397881

\section{HAL Id: hal-02397881 https://hal.science/hal-02397881}

Submitted on 7 Mar 2021

HAL is a multi-disciplinary open access archive for the deposit and dissemination of scientific research documents, whether they are published or not. The documents may come from teaching and research institutions in France or abroad, or from public or private research centers.
L'archive ouverte pluridisciplinaire HAL, est destinée au dépôt et à la diffusion de documents scientifiques de niveau recherche, publiés ou non, émanant des établissements d'enseignement et de recherche français ou étrangers, des laboratoires publics ou privés. 


\title{
Synthesis of zeolite SSZ-24 using a catalytic amount of SSZ-13 seeds
}

Received 00th January 20xx, Accepted 00th January 20xx DOI: $10.1039 / \times 0 \times x 00000 x$

\author{
Lingxue Tang, ${ }^{\text {a }}$ Kok-Giap Haw, ${ }^{\text {a }}$ Ping He, ${ }^{\text {a }}$ Qianrong Fang, ${ }^{\text {a }}$ Shilun Qiu, ${ }^{a}$ Valentin Valtcheve, ${ }^{\mathrm{a}}{ }^{*}$
}

SSZ-24 proved to be a zeolite with poor synthesis reproducibility and slow crystallization rate. The present study deals with the preparation of SSZ-24 by a seed-assisted approach. SSZ-13 and SSZ-24 zeolites are employed as seeds and the impact of seeds content on the formation of SSZ-24 studied. Both types of zeolite accelerate the zeolite nucleation, shorten crystallization time, and lead to the formation of pure and highly crystalline SSZ-24. However, the use of SSZ-13 seeds is more efficient in terms of rapid crystallization and crystallinity level. Pure and highly crystalline SSZ-24 is readily obtained even though the amount of SSZ-13 seeds has been decreases to a "catalytic level", i.e. 0.3 wt.\%. The higher seeding power of SSZ-13 seeds is attributed to the presence of framework Al, which stabilizes structural elements that promote the SSZ24 nucleation.

\section{Introduction}

Zeolites are extensively used in different areas of the chemical industry, such as shape selective catalysis, gas adsorption and separation, and ion exchange. ${ }^{1-6}$ Crystalline structure and chemical compositions determine the properties and practical applications of a zeolite. However, the use of a particular zeolite does not depend solely on its properties. The production conditions in terms of operational simplicity, short production time and reactants employed are often decisive for the large-scale use of a particular zeolite. Hence, the optimization of synthesis parameters that lead to a more efficient and low-cost zeolite synthesis deserves particular attention.

It is almost 60 years since the first seeded zeolite synthesis was reported. ${ }^{7}$ In the $1960 \mathrm{~s}$, Kerr investigated the factors affecting the formation of zeolites A, B, and X using 10-15 wt.\% seeds. ${ }^{7,8}$ Later, Mirskii proposed a kinetic model of zeolite formation in the presence of seeds. ${ }^{9}$ Kacirek employed seeds to achieve the separation of nucleation and growth, the amount of the added faujasite seeds nuclei with respect to the whole amount of the crystalline products was 2.5 to 3.0 wt. \%. ${ }^{10}$ Seeds are commonly used when zeolite synthesis reproducibility is poor since the seeded synthesis is less sensitive to the reactants and crystallization conditions used.

Further, the seed-assisted approach is used to reduce the cost

\footnotetext{
a. State Key Laboratory of Inorganic Synthesis and Preparative Chemistry, Jilin University, Changchun 130012, China.

b. Normandie Univ, ENSICAEN, UNICAEN, CNRS, Laboratoire Catalyse et Spectrochimie, 6 Marechal Juin, 14050 Caen, France.

+Email: valentin.valtchev@ensicaen.fr

Electronic Supplementary Information (ESI) available: [details of any supplementary information available]. See DOI: 10.1039/x0xx00000x
}

and enable the development of environmentally friendly production processes of relevant zeolites. ${ }^{11,12}$ Important issues as the reduction of the synthesis time, elimination of impurities, controlling the particle size are also positively influenced by seeding. ${ }^{13-20}$ Seeding is also commonly employed in the preparation of zeolite membranes and 3D structures. ${ }^{21}$ The seed content in zeolite synthesis vary between 5 and 15 wt.\% approximately, and the use of 1 to $3 \mathrm{wt} . \%$ is scracely reported.

SSZ-24 is a high-silica, large-pore molecular sieve isostructural with AIPO-5 (AFI) aluminophoshpate. ${ }^{22}$ SSZ-24 was first synthesized by Zones et al. using 1trimethylammonioadamantane as structure directing agent (SDA). ${ }^{23}$ The crystallization of SSZ-24 is substantially longer in respect to the most of high silica zeolites. Typically, the synthesis of SSZ-24 requires more than 10 days at $150{ }^{\circ} \mathrm{C}$ using $\mathrm{N}, \mathrm{N}, \mathrm{N}$-trimethyl-1-adamantanamine cation as an organic structure-directing agent. ${ }^{23-26}$

Over past decades, many efforts have been made to optimize the crystallization of zeolite SSZ-24. Zones et al. synthesized boron-containing SSZ-24 by using a calcined form of boronsubstituted zeolite beta ([B]-BEA) as primary silica sources. ${ }^{27}$ Lobo and Davis reported the synthesis of [B]-SSZ-24 using $\mathrm{N}(16)$-methylsparteinium (MeSPA) as SDA and sodium borate as the source of boron. ${ }^{28}$ In the later case, the calcined [B]BEA did not work as precursors for [B]-SSZ-24 synthesis. Maekawa et al. studied the phase transformation of [Al]-BEA to [Al]-SSZ-24 by using MeSPA as OSDA. ${ }^{29,30}$ Valtchev et al. reported a synthesis of zeolite SSZ-24 with 5 wt.\% seeds. ${ }^{31}$ Peng et al. reported a fast synthesis of zeolite SSZ-24 at $210^{\circ} \mathrm{C}$ in $60 \mathrm{~min}$ by fast heating in a stainlesssteel tubular reactor with 10 wt.\% SSZ-24 seeds. ${ }^{32}$ However, such fast synthesis 
method involved special equipment and a series of complicated and time consuming pre-treatment steps before the hydrothermal treatment, which limits its practical application. For instance, 2 days stirring at room temperature was required for homogenization of the gel followed by an aging step at $95^{\circ} \mathrm{C}$ for 3 days and then synthesis in an oil bath at $210^{\circ} \mathrm{C}$ for $60 \mathrm{~min}$.

Here we report the use of catalytic amounts of seeds for rapid synthesis of zeolite SSZ-24. Two types of seeds, zeolite SSZ-24 and SSZ-13, were employed. The structure similarity, i.e. the abundant presence of 6-rings, in the AFI- (SSZ-24) and CHA(SSZ-13) type structures is the reason to employ SSZ-13 and compare its performance in respect to the SSZ-24 seeds. The ultimate goal of this study is to reduce both the mass of seeds used and the crystallization time, which would bring substantial practical advantages. To the best of our knowledge, no other synthesis of SSZ-24 under autogenous pressure hydrothermal conditions reported to date is shorter than 1 day and required only a catalytic amount of seeds.

\section{Experimental}

\section{Materials}

All chemicals and materials used are from commercially available sources and employed without further purification. Potassium hydroxide ( $\mathrm{KOH} 98 \%$, Aladdin Chemistry), Lithium hydroxide (LiOH 98\%, Sigma-Aldrich), Sodium hydroxide $(\mathrm{NaOH}$ 98\%, Aladdin Chemistry), Cesium hydroxide ( $\mathrm{CsOH} 50$ wt.\% in water, Adamas-beta), N,N,N-trimethyl-1-adamantammonium hydroxide (TMAD 25\%, Xikai Industry), Deionized water, Aluminum metal powder ( $99.5 \%$, Aladdin Chemistry), Colloidal silica (Ludox HS-40, 40 wt.\% $\mathrm{SiO}_{2}$, Sigma-Aldrich) and fumed silica $\left(\mathrm{SiO}_{2}\right.$, Sigma-Aldrich). The zeolite Beta with $\mathrm{Si} / \mathrm{Al}=15$, which was used as a silliiiica-alumina source in the synthesis of SSZ-13, was purchased from Changchun Third Party Pharmaceutical Technology. A home-made SSZ-24 and SSZ-13 were used as seeds without prior calcination.

\section{Conventional hydrothermal synthesis of SSZ-24}

The reference SSZ-24 sample, denoted CS (conventional synthesis), was obtained from a gel with composition 0.1TMAD: $0.15 \mathrm{KOH}$ : $1 \mathrm{SiO}_{2}: 44 \mathrm{H}_{2} \mathrm{O}$. In a typical synthesis, $1.5 \mathrm{~g}$ fumed silica, $0.21 \mathrm{~g} \mathrm{KOH}$, and $1.51 \mathrm{~g}$ TMAD were mixed with $18.9 \mathrm{~g} \mathrm{H}_{2} \mathrm{O}$ under stirring. ${ }^{24}$ The resulting gel was charged into a Teflon-lined stainless-steel autoclave and hydrothermally treated at $150{ }^{\circ} \mathrm{C}$ for 22 days. The final product was collected by vacuum filtration and washed with deionized water until a near neutral $\mathrm{pH}$ and dried overnight at 60 ${ }^{\circ} \mathrm{C}$. The sample was calcined at $550^{\circ} \mathrm{C}$ (at $60^{\circ} \mathrm{C} \cdot \mathrm{h}^{-1} \mathrm{ramp}$ ) in air flow for $6 \mathrm{~h}$.

\section{Synthesis of SSZ-13 and SSZ-24 seeds}

SSZ-13 was prepared according to reference 33 and used for seeding. The SSZ-13 seeds used in this study were prepared from a gel with molar composition $1 \mathrm{SiO}_{2}: 0.05 \mathrm{Al}_{2} \mathrm{O}_{3}: 0.18 \mathrm{~K}_{2} \mathrm{O}: 0.31 \mathrm{TMAD}: 30 \mathrm{H}_{2} \mathrm{O}$, where 1.7 g zeolite beta and the TMAD solution were mixed (solid/liquid weight ratio $=0.14)$ under stirring for $2 \mathrm{~h}$ at room temperature. The autoclave was heated at $150{ }^{\circ} \mathrm{C}$ for $24 \mathrm{~h}$. After the crystallization step, the solid product was collected by vacuum filtration and washed thoroughly with deionized water until a near neutral $\mathrm{pH}$ and then dried overnight at $60^{\circ} \mathrm{C}$.

The SSZ-24 seeds used in this study were prepared from a gel with molar composition 0.06TMAD: $0.1 \mathrm{NaOH}: \mathrm{SiO}_{2}$ : $21.1 \mathrm{H}_{2} \mathrm{O}$, where 0.3 wt.\% of SSZ-13 seeds prepared according to the procedure described above were added. In a typical synthesis, $4.4 \mathrm{~g}$ colloidal silica (Ludox HS-40), $0.1 \mathrm{~g}$ sodium hydroxide and $0.005 \mathrm{~g} \mathrm{SSZ}-13$ seeds were mixed with $1.6 \mathrm{~g}$ TMAD solution under stirring, the autoclave was heated at $100{ }^{\circ} \mathrm{C}$ for $1 \mathrm{~h}$ and at $180^{\circ} \mathrm{C}$ for $22 \mathrm{~h}$. The final product was collected by vacuum filtration and washed with deionized water until a near neutral $\mathrm{pH}$ and dried overnight at $60^{\circ} \mathrm{C}$. Both SSZ-24 and SSZ-13 seeds were used without prior calcination.

\section{Synthesis of zeolite SSZ-24 using SSZ-24 seeds}

The synthesis of SSZ-24 was studied in the presence of $\mathrm{KOH}$ and $\mathrm{NaOH}$.

KOH system: Synthesis gel was prepared according to the following composition 0.1TMAD: $0.15 \mathrm{KOH}$ : $1 \mathrm{SiO}_{2}: 44 \mathrm{H}_{2} \mathrm{O}$ and 5 wt.\% of SSZ-24 seeds. The seed content (in wt.\%) is calculated on the $\mathrm{SiO}_{2}$ basis in the starting gel. In a typical synthesis, $1.5 \mathrm{~g}$ fumed silica, $0.21 \mathrm{~g} \mathrm{KOH}$, and $1.51 \mathrm{~g} \mathrm{TMAD}$ were mixed with $18.9 \mathrm{~g} \mathrm{H}_{2} \mathrm{O}$ under stirring. $0.075 \mathrm{~g} \mathrm{SSZ}-24$ seeds were added into the above gel. The synthesis was performed in a Teflonlined stainless-steel autoclave and hydrothermally treated at $150{ }^{\circ} \mathrm{C}$ for $24 \mathrm{~h}$ and $72 \mathrm{~h}$. The final product was collected by vacuum filtration and washed with deionized water until a near neutral $\mathrm{pH}$ and dried overnight at $60^{\circ} \mathrm{C}$.

$\mathrm{NaOH}$ system: Synthesis gel was prepared according to the following composition 0.06TMAD: $0.10 \mathrm{NaOH}: x \mathrm{SiO}_{2}: 21.1 \mathrm{H}_{2} \mathrm{O}$, when $\mathrm{x}$ is 1.76 mole, the mass of seeds added was $0.0,0.3,1.2$, 3.0 (wt.\%); when $\mathrm{x}$ is 1.20 mole, the mass of seeds added was 4.2 (wt.\%). The seed content (in wt.\%) is calculated on the $\mathrm{SiO}_{2}$ basis in the starting gel. In a typical synthesis, $4.4 \mathrm{~g}$ colloidal silica (Ludox HS-40) and $0.1 \mathrm{~g} \mathrm{NaOH}$ was mixed with $1.6 \mathrm{~g}$ TMAD solution under stirring. $0.07 \mathrm{~g} \mathrm{SSZ-24}$ seeds were added into the above gel. The gel was then mixed vigorously for 10 $\mathrm{min}$. The resulting reaction mixture was charged into a Teflonlined, stainless-steel autoclaves. Before the hydrothermal treatment, the mixture was aged at $100{ }^{\circ} \mathrm{C}$ for $1 \mathrm{~h}$. Then autoclaves were heated statically under autogenous pressure for $22 \mathrm{~h}$ at $180^{\circ} \mathrm{C}$. The final product was collected by vacuum filtration and washed with deionized water until a near neutral $\mathrm{pH}$ and dried overnight at $60{ }^{\circ} \mathrm{C}$. The sample was calcined at $550{ }^{\circ} \mathrm{C}$ (at $60{ }^{\circ} \mathrm{C} \cdot \mathrm{h}^{-1} \mathrm{ramp}$ ) in air flow for $6 \mathrm{~h}$ and denoted as $\mathrm{S} 24-\mathrm{Y}$, where S24 represents synthesis in the presence of SSZ24 seeds, and $Y$ is the numerical order of a series of experiments at variable syntheses conditions, as shown in Table 1.

\section{Synthesis of zeolite SSZ-24 using SSZ-13 seeds}

Similar to the previous part, the synthesis of SSZ-24 was studied in the presence of $\mathrm{KOH}$ and $\mathrm{NaOH}$. 
KOH system: Synthesis gel with composition 0.1TMAD: $0.15 \mathrm{KOH}: 1 \mathrm{SiO}_{2}: 44 \mathrm{H}_{2} \mathrm{O}$ and 5 wt.\% of SSZ-13 seeds was prepared. The seed content (in wt.\%) is calculated on the $\mathrm{SiO}_{2}$ basis in the starting gel. In a typical synthesis, $1.5 \mathrm{~g}$ fumed silica, $0.21 \mathrm{~g} \mathrm{KOH}$, and $1.51 \mathrm{~g}$ TMAD were mixed with $18.9 \mathrm{~g}$ $\mathrm{H}_{2} \mathrm{O}$ under stirring. $0.075 \mathrm{~g} \mathrm{SSZ}-13$ seeds were added into the above gel. The synthesis was performed in a Teflon-lined stainless-steel autoclave and hydrothermally treated at $150{ }^{\circ} \mathrm{C}$ for $24 \mathrm{~h}$ and $72 \mathrm{~h}$. The final product was collected by vacuum filtration and washed with deionized water until a near neutral $\mathrm{pH}$ and dried overnight at $60^{\circ} \mathrm{C}$.

$\mathrm{NaOH}$ system: Synthesis gel was prepared using the following composition xTMAD: yNaOH: $\mathrm{SiO}_{2}: \mathrm{zH}_{2} \mathrm{O}$, where $\mathrm{x}=0-0.08, \mathrm{y}=$ $0-0.3, z=21.1-28.7$ (moles); and the seed content was varied between 0.0 and $9.0 \mathrm{wt} . \%$ (Table 2 ). The seed content (in wt.\%) is calculated on the $\mathrm{SiO}_{2}$ basis in the starting gel. In a typical synthesis, $4.4 \mathrm{~g}$ colloidal silica (Ludox HS-40) and $0.1 \mathrm{~g}$ $\mathrm{NaOH}$ was mixed with $1.6 \mathrm{~g}$ TMAD solution under stirring. The $0.005 \mathrm{~g}$ seeds were added into the gel. The gel was then mixed vigorously for $10 \mathrm{~min}$ and charged into a Teflon-lined stainlesssteel autoclave. Before the high temperature hydrothermal treatment, the mixture was aged at $100{ }^{\circ} \mathrm{C}$ for $1 \mathrm{~h}$. Then autoclaves were heated statically under autogenous pressure for $22 \mathrm{~h}$ at $180{ }^{\circ} \mathrm{C}$. The final product was collected by vacuum filtration and washed with deionized water until a near neutral $\mathrm{pH}$ and dried overnight at $60{ }^{\circ} \mathrm{C}$. The sample was denoted as S13-X, where S13 represents synthesis in the presence of SSZ13 seeds, and $X$ is the numerical order of a series of experiments at variable syntheses conditions, as shown in Table 2.

Influence of the alkaline metal (Li, $\mathrm{Na}, \mathrm{K}, \mathrm{Cs}$ ) on the synthesis of SSZ-24: Synthesis gel was prepared according to the following composition 0.06TMAD: 0.1MOH: $\mathrm{SiO}_{2}: 21.1 \mathrm{H}_{2} \mathrm{O}, \mathrm{M}=\mathrm{Li}, \mathrm{Na}, \mathrm{K}, \mathrm{Cs}$, and $0.3 \mathrm{wt} . \%$ of SSZ-13 seeds. The gel was then mixed vigorously for $10 \mathrm{~min}$ and then charged into Teflon-lined stainless-steel autoclaves. Before the high temperature hydrothermal treatment, the mixture was aged at $100{ }^{\circ} \mathrm{C}$ for $1 \mathrm{~h}$. Then autoclaves were heated statically under autogenous pressure for $22 \mathrm{~h}$ at $180^{\circ} \mathrm{C}$. The final product was collected by vacuum filtration and washed with deionized water until a near neutral $\mathrm{pH}$ and dried overnight at 60 ${ }^{\circ} \mathrm{C}$.

Crystal growth kinetics of SSZ-24: The relative crystallinity of the samples prepared at different period of crystallization were determined by XRD analysis using the peak area at $7.42^{\circ}$ $2 \theta$ in relative to the reference SSZ-24 sample (CS). For more accurate analysis, the XRD patterns of the calcined samples were used.

The yield of SSZ-24 was calculated by the following equation:

$$
\begin{aligned}
& \text { yield }(\%)= \\
& \frac{\text { SSZ }-24(\mathrm{~g})}{\text { Si source }(\mathrm{g})+\text { seeds }(\mathrm{g})} \cdot 100
\end{aligned}
$$

\section{Characterization}

Powder X-ray diffraction (PXRD) analysis was performed on a PANalytical B.V. Empyrean powder diffractometer at $40 \mathrm{kV}$ and 40 $\mathrm{mA}$ using $\mathrm{Cu}$ Ka radiation $(\lambda=1.5418 \AA$ ) over the range of $2 \theta=4.0-$ $40.0^{\circ}$. Thermogravimetric analysis (TGA) was performed using a SHIMADZU DTG-60 thermal analyser system from 30 to $650{ }^{\circ} \mathrm{C}$ under an air atmosphere at a heating rate of $10{ }^{\circ} \mathrm{C} \mathrm{min}-1$. A JEOL JSM6700 scanning electron microscope was used to study the morphology of the samples. Elemental analysis of the sample was measured by Energy Dispersive X-Ray Fluorescence Spectrometer (EDX) operated at JEM-2100F. Nitrogen and carbon dioxide physisorption analyses were performed with a Quantachrome Autosorb-IQ analyzer with ultra-high-purity nitrogen gas $(99.999 \%$ purity) at $77 \mathrm{~K}$ and $\mathrm{CO}_{2}$ gas (99.999\% purity) at $273 \mathrm{~K}$ and $298 \mathrm{~K}$. The calcined samples were analyzed after degassing at $300{ }^{\circ} \mathrm{C}$. The specific surface areas $\left(\mathrm{S}_{\mathrm{BET}}\right)$ were obtained using the BrunauerEmmett-Teller (BET) equation. The microporous volume $\left(V_{\text {mic }}, \mathrm{cm}^{3}\right.$ $\left.\mathrm{g}^{-1}\right)$ and external surface area $\left(S_{\mathrm{ext}}, \mathrm{m}^{2} \mathrm{~g}^{-1}\right)$ were obtained from the t-plot based on the Harkins-Jura equation.

\section{Results and discussion}

\subsection{Conventional hydrothermal synthesis of SSZ-24}

Our preliminary study of SSZ-24 crystallization was based on the gel composition reported in reference 24. A highly crystalline SSZ-24 was obtained after 22 days crystallization at $150^{\circ} \mathrm{C}$ (Fig. S1). The adition of $5 \mathrm{wt} . \%$ SSZ-24 seeds to this system did not show the expected positive effect in term of substantially imporved crystallization rate. After $24 \mathrm{~h}$ crystallization amorphous and unidentified phase was found in the solid, while after $72 \mathrm{~h}$ traces of SSZ-24 with a large amount of amorphous material was observed (Fig. S2). In contrast, the addition of 5 wt.\% SSZ-13 seeds to the system resulted in crystalline product after $72 \mathrm{~h}$ of synthesis (Fig. S3). However, in a mixture of SSZ-24, SSZ-13 and SSZ-31 was synthesized. Thus, further optimization of the initial gel was required in order to obtainpure SSZ-24.

\subsection{Synthesis of zeolite SSZ-24 using SSZ-24 seeds}

We have studied the performance of SSZ-24 seeds in the formation of pure and highly crystalline AFI-type zeolite in a $\mathrm{NaOH}$ system. Table 1 shows the synthesis conditions and the obtained products. The synthesis containing below 1.2 wt.\% seeds did not yield a crystalline product (Run S24-1, S24-2). At higher seeds loading, i.e. 3.0 wt.\%, SSZ-24 and crystoballite type $\mathrm{SiO}_{2}$ were formed (Run S244). A pure SSZ-24 was obtained after the increase of seeds content to 4.2 wt.\% while decreasing the $\mathrm{SiO}_{2}$ content in the gel to 1.20 mole (Run S24-5). XRD pattern (Fig. 1 left) and SEM micrograph (Fig.1 right) of S24-5 showed that a pure zeolite SSZ-24 was obtained and the crystals were relatively uniform in size. However, a careful SEM inspection indicated that some impurities were present in the sample. The amount of these impurities is below 3 wt.\% since no other crystalline phase was detected in the XRD pattern of the solid. It should also be mentioned that the preliminary aging at $100{ }^{\circ} \mathrm{C}$ is indispensable to obtain pure SSZ-24. Without preliminary aging the formation of SSZ-31 as an impurity is observed (Fig. S4). 
Table 1 Synthesis conditions and products of seeded SSZ-24 synthesis at 180 ${ }^{\circ} \mathrm{C}$ for $22 \mathrm{~h}$.

\begin{tabular}{|c|c|c|c|c|c|}
\hline \multirow[b]{2}{*}{ Run } & \multicolumn{4}{|c|}{ Synthesis conditions } & \multirow{2}{*}{$\begin{array}{c}\text { Product(s) } \\
\text { Crystalline phase(s) }\end{array}$} \\
\hline & $\begin{array}{c}\mathrm{SiO}_{2} \\
\text { (mole) }\end{array}$ & $\begin{array}{l}\text { Seeds } \\
\text { (wt.\%) }\end{array}$ & $\begin{array}{c}\mathrm{NaOH} / \\
\mathrm{SiO}_{2}\end{array}$ & $\begin{array}{l}\text { TMAD/ } \\
\mathrm{SiO}_{2}\end{array}$ & \\
\hline S24-1 & 1.76 & 0.0 & 0.10 & 0.06 & Amorphous \\
\hline S24-2 & 1.76 & 0.3 & 0.10 & 0.06 & Amorphous \\
\hline S24-3 & 1.76 & 1.2 & 0.10 & 0.06 & SSZ-24, $\mathrm{SiO}_{2}, \mathrm{SSZ}-31$ \\
\hline S24-4 & 1.76 & 3.0 & 0.10 & 0.06 & $\mathrm{SSZ}-24, \mathrm{SiO}_{2}$ \\
\hline S24-5 & 1.20 & 4.2 & 0.10 & 0.06 & SSZ-24 \\
\hline
\end{tabular}
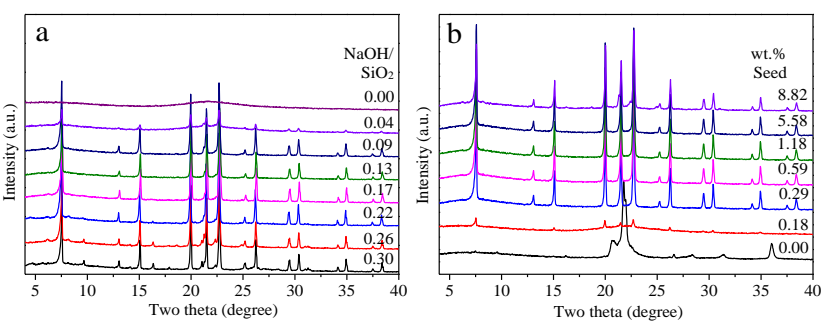

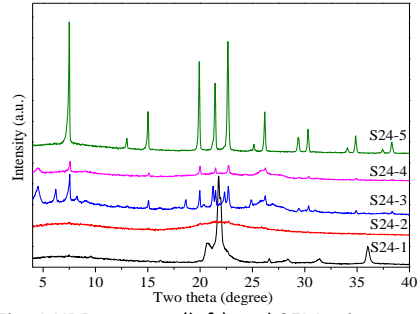

Fig. 1 XRD pattern (left) and SEM micrograph (right) of SSZ-24 obtained by using SSZ-24 as seed.

\subsection{Synthesis of zeolite SSZ-24 using SSZ-13 seeds}

Structure similarities between SSZ-24 and SSZ-13, i.e. the abundant presence of 6 member rings units, inspire us to try the use of SSZ-13 seeds in the synthesis of SSZ-24.

All important factors controlling SSZ-24 crystallization were studied. First, we have investigated the impact of sodium on the formation of SSZ-24 in $\mathrm{NaOH}$ system in the presence of 0.6 wt. \% SSZ-13 seeds. The experimental conditions and the results are summarized in Table 2 (Run S13-1 to S13-8) and the XRD patterns are presented in Fig. 2a. When $\mathrm{NaOH} / \mathrm{SiO}_{2} \geq 0.26$, mixed phases of zeolite SSZ-13, SSZ-24, SSZ-31 were formed (Run S13-1, S13-2). Pure well crystalline SSZ-24 was obtained at $0.04 \leq \mathrm{NaOH} / \mathrm{SiO}_{2} \leq 0.13$ (Run S13-5, S13-6, S13-7). It is worth noting that $\mathrm{NaOH}$ is crucial in SSZ24 synthesis since without it $\left(\mathrm{NaOH} / \mathrm{SiO}_{2}=0\right)$ AFI-type material was not formed (Run S13-8).
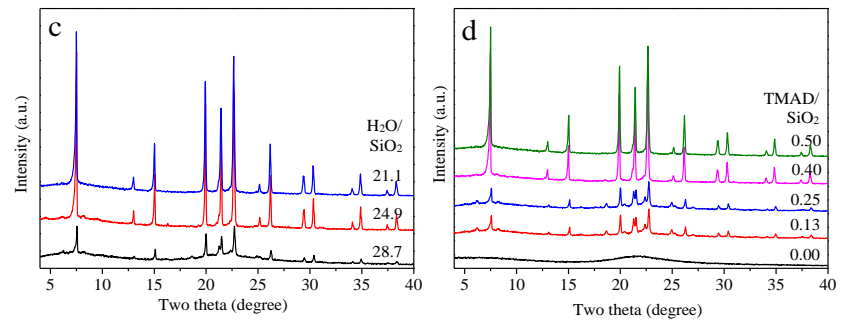

Fig. 2 XRD patterns of SSZ-24 synthesized at different content of $\mathrm{NaOH}$ (a), SSZ-13 seeds (b), Water (c) and TMAD (d).

The impact of seed content was studied in experiments S13-9 to $\mathbf{S 1 3 - 1 5}$ (Table 2). The XRD patterns are presented Fig. $2 \mathrm{~b}$. Pure SSZ-24 phase was constantly obtained even at seed content as low as 0.3 wt.\% (Run S13-11). Noteworthy, at seed content of 0.2 wt.\% still SSZ-24 can be observed in the product, but the amount of crystalline material was very low. Also, the crystallization rate decreased substantially. On the other hand, the use of 0.3 wt.\% seeds (Run S13-11), resulted in SSZ-24 materials with $90 \%$ crystallinity. No crystallization was observed in the non-seeded system (Run S13-9).

In the introduction section, it was pointed out that the zeolite synthesis required $\geq 3-5$ wt.\% seeds. The reduction of the seed content below $3 \mathrm{wt} . \%$ is rarely reported. The present study showed that upon optimization of the synthesis conditions, the mass of seeds could be reduced below $1 \mathrm{wt} . \%$ in respect to the silica content in the gel. Such a low seed content we consider as a "catalytic" since it is negligible with respect to

Table 2 Conditions of SSZ-24 synthesis with SSZ-13 seed at $180^{\circ} \mathrm{C}$ for $22 \mathrm{~h}$ and the corresponding products.

\begin{tabular}{|c|c|c|c|c|c|c|}
\hline \multirow[b]{2}{*}{ Run } & \multicolumn{4}{|c|}{ Synthesis conditions (mole ratio) } & \multicolumn{2}{|c|}{ Product (s) } \\
\hline & Seed (wt.\%) & $\mathrm{NaOH} / \mathrm{SiO}_{2}$ & $\mathrm{TMAD} / \mathrm{SiO}_{2}$ & $\mathrm{H}_{2} \mathrm{O} / \mathrm{SiO}_{2}$ & Phase (s) & Crystallinity (\%) \\
\hline S13-1 & 0.6 & 0.30 & 0.08 & 24.9 & SSZ-13, SSZ-24, SSZ-31 & - \\
\hline S13-2 & 0.6 & 0.26 & 0.08 & 24.9 & SSZ-13, SSZ-24, SSZ-31 & - \\
\hline S13-3 & 0.6 & 0.22 & 0.08 & 24.9 & SSZ-24, SSZ-31 & - \\
\hline S13-4 & 0.6 & 0.17 & 0.08 & 24.9 & SSZ-24, SSZ-31 & - \\
\hline S13-5 & 0.6 & 0.13 & 0.08 & 24.9 & SSZ-24 & 92 \\
\hline S13-6 & 0.6 & 0.09 & 0.08 & 24.9 & SSZ-24 & 88 \\
\hline S13-7 & 0.6 & 0.04 & 0.08 & 24.9 & SSZ-24 & 28 \\
\hline S13-8 & 0.6 & 0.00 & 0.08 & 24.9 & Amorphous & - \\
\hline S13-9 & 0.0 & 0.09 & 0.08 & 24.9 & Layered silicate & - \\
\hline S13-10 & 0.2 & 0.09 & 0.08 & 24.9 & SSZ-24 & 17 \\
\hline S13-11 & 0.3 & 0.09 & 0.08 & 24.9 & SSZ-24 & 82 \\
\hline S13-12 & 0.6 & 0.09 & 0.08 & 24.9 & SSZ-24 & 88 \\
\hline S13-13 & 1.2 & 0.09 & 0.08 & 24.9 & SSZ-24 & 89 \\
\hline S13-14 & 6.0 & 0.09 & 0.08 & 24.9 & SSZ-24 & 92 \\
\hline S13-15 & 9.0 & 0.09 & 0.08 & 24.9 & SSZ-24 & 92 \\
\hline S13-16 & 0.3 & 0.09 & 0.08 & 28.7 & SSZ-24 & 43 \\
\hline S13-17 & 0.3 & 0.09 & 0.08 & 21.1 & SSZ-24 & 90 \\
\hline S13-18 & 0.3 & 0.09 & 0.06 & 21.1 & SSZ-24 & 91 \\
\hline S13-19 & 0.3 & 0.09 & 0.04 & 21.1 & SSZ-24, SSZ-31 & - \\
\hline $\mathrm{S} 13-20$ & 0.3 & 0.09 & 0.02 & 21.1 & SSZ-24, SSZ-31 & - \\
\hline S13-21 & 0.3 & 0.09 & 0.00 & 21.1 & Amorphous & - \\
\hline
\end{tabular}

4 | J. Name., 2012, 00, 1-3

This journal is (C) The Royal Society of Chemistry 20xx 


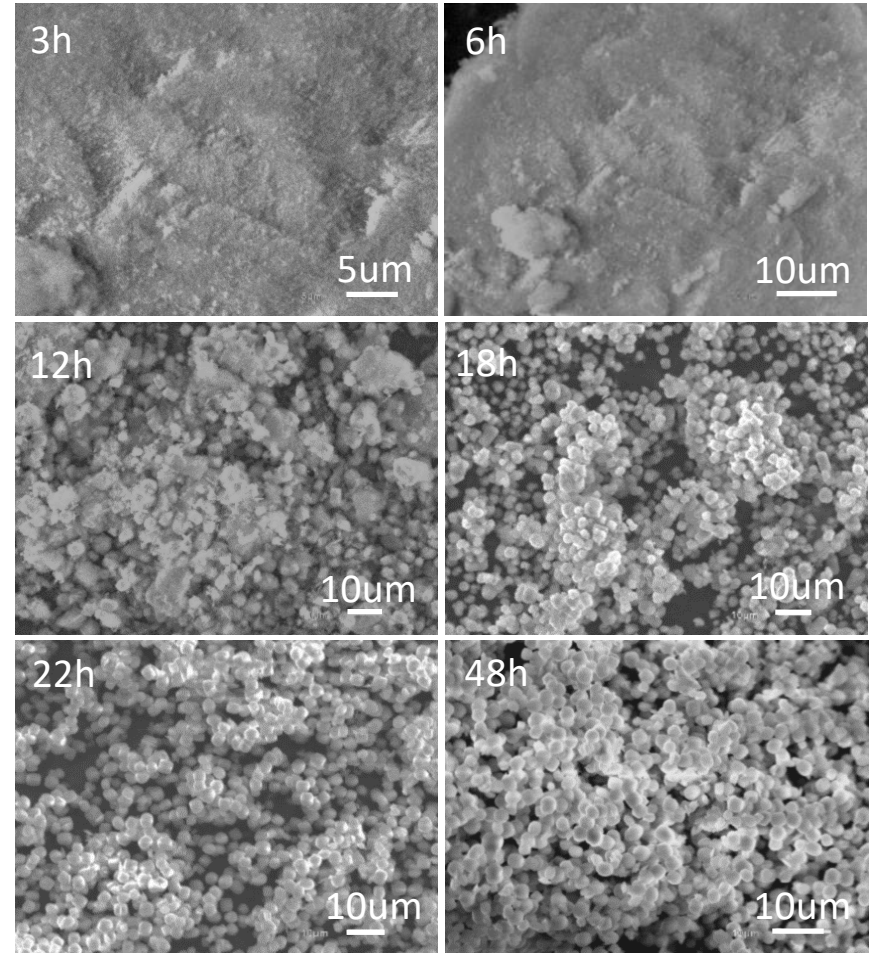

Fig. 3 SEM micrographs of of the series of samples S13-18 after 1, 3, 6, 12, 18, 22 and $48 \mathrm{~h}$ of hydrothermal synthesis.

the mass of the gel.

The water content had a pronounced affect on the seeded SSZ24 synthesis (Table 2, S13-11, S13-16, S13-17). For instance, as water content was increased to $\mathrm{H}_{2} \mathrm{O} / \mathrm{SiO}_{2}=28.7$, the crystallinity of SSZ-24 decreased to $43 \%$ (Run S13-16), while the crystallinity reached $90 \%$ (Run $\mathrm{S} 13-17$ ) when the water content decreased to $\mathrm{H}_{2} \mathrm{O} / \mathrm{SiO}_{2}=21.1$ (Fig. 2c).

The effect of TMAD on the synthesis of SSZ-24 was studied in the series $\mathrm{S} 13-17$ to $\mathrm{S} 13-21$ synthesis (Table 2). When $\mathrm{TMAD} / \mathrm{SiO}_{2}$ mole ratio $\geq 0.06$ (Run S13-17 and S13-18), a pure SSZ-24 was obtained. SSZ-31 was present as an impurity when $\mathrm{TMAD} / \mathrm{SiO}_{2}<0.06$ (Run S13-19 and S13-20) and only amorphous was found in the TMAD-free system (Run S13-21). The crystal growth kinetics of SSZ-24 in SSZ-13 seeded system was followed by SEM (Fig. 3). After $12 \mathrm{~h}$ large amorphous particles and crystals, the later are not well shaped, can be seen. The crystals are much better shaped after $18 \mathrm{~h}$, but still some amorphous can be observed in the solid product. No traces of amorphous material are seen in the product after 22 $\mathrm{h}$ crystallization. The extension of the crystallization time to 48 $\mathrm{h}$ resulted in larger crystals, which is a consequence of the Ostwald repining.

In general, the use of SSZ-13 seeds in the crystallization of SSZ24 is much more efficient with respect to the genuine SSZ-24 seeds. Often the crystal size and morphological feature influence the seed performance. However, the employed SSZ13 and SSZ-14, where farely similar in morphology. Therefore, the seeding power of SSZ-13 is likely to be related to their composition. Hence we consider that the Al-containing SSZ-13 is more stable under conditions employed. More precisely, the

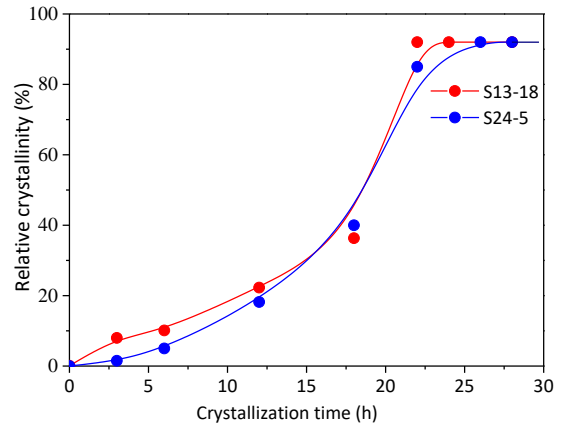

Fig. 4 Crystal growth kinetics of SSZ-24 synthesized with SSZ-13 (S13-18) and SSZ-24 (S24-5) seeds.

framework aluminum is providing a stable configuration which retains the structure elements that promote the formation of SSZ-24. On the contrary, the all-silica SSZ-24 was readily dissolved in basic medium and lost its seeding power. In order to gain more insight into the phase transformation during the crystallization process, we have studied the crystal growth kinetics of SSZ-24 at $180^{\circ} \mathrm{C}$ (Fig. 4). The relative crystallinity of the calcined samples was determined by the peak area at $7.42^{\circ}$ $2 \theta$ under XRD patterns (Fig. S5) in relative to the reference SSZ-24 sample (CS). The reaction rate of using SSZ-13 (Run S1318) as seeds is higher and a complete crystallization was obtained after $22 \mathrm{~h}$, faster than the one using SSZ-24 (Run S24$5)$ as seeds ( $28 \mathrm{~h}$ ). Consider the conventional synthesis of SSZ24 required 22 days. ${ }^{24}$ The employment of seeds, as shown in the present study, improves substantially the crystallization rate of SSZ-24.

Generally, zeolites are synthesized in the presence of alkali metal cations, which influence not only the crystallization rate and framework Si/Al ratio but also the crystal size and

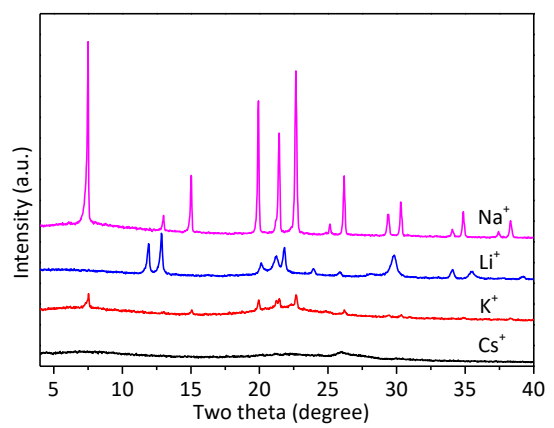

Fig. 5 XRD patterns of SSZ-24 synthesized with different alkaline metal cations at $180^{\circ} \mathrm{C}$ for $22 \mathrm{~h}$.

morphology. ${ }^{34,35}$ Since alkali metal cation plays an essential role in the zeolite synthesis, the effect of $\mathrm{Li}^{+}, \mathrm{Na}^{+}, \mathrm{K}^{+}, \mathrm{Cs}^{+}$on the formation of SSZ-24 were studied. Sodium is the most widely used alkali cation in zeolite synthesis. It promotes the formation of a number of zeolites and contributing to a rapid crystal growth rate. ${ }^{37}$ Potassium is also largely used in zeolite 
synthesis with more pronounced structure specificity. In contrast, $\mathrm{Li}^{+}$and $\mathrm{Cs}^{+}$hardly promote the crystallization of zeolite structures. ${ }^{38}$ A previous study showed that pure SSZ-24 was obtained from the K-TMAD system, while the replacement of $\mathrm{K}^{+}$with $\mathrm{Na}^{+}$would lead to bi-phases product. ${ }^{36}$ However, when as-synthesized SSZ-13 seeds were used, the $\mathrm{Na}$ containing system yeilded highly crystalline SSZ-24 within $24 \mathrm{~h}$. The crystallinity of K-SSZ-24 was lower with respect to Na-SSZ24 (Fig. 5) and the increase pf $\mathrm{K}^{+}$content hindered the formation of SSZ-24 (Fig. S6a). The extension of the reaction time of $\mathrm{K}^{+}$-containinh system to 2 days resulted in highly crystalline SSZ-24, however zeolite SSZ-31 was formed as a side product (Fig. S6b). In contract, SSZ-24 was constantly obtained in $\mathrm{Na}^{+}$system even after 3 days of synthesis, revealing the essential role of the alkaline cation in SSZ-24 synthesis. In summary, SSZ-24 was successfully obtained in the presence of $\mathrm{Na}^{+}$and $\mathrm{K}^{+}$, while to $\mathrm{Li}^{+}$yielded an unknown phase and in the case of $\mathrm{Cs}^{+}$no crystalline product was found (Fig. 5).

For the sake of comparison the characteristics of the two best SSZ-24 samples obtained with SSZ-13 (S13-18) and SSZ-24 (S24-5) seeds were compared. Both samples showed X-ray crystallinity higher than $90 \%$. Thermogravimetrical (TG) analysis showed similar wight losses, $12.6 \mathrm{wt} . \%$ and $12.9 \mathrm{wt} . \%$ for S13-18 and S24-5, respectively (Figure S7). The amount of $\operatorname{TMAD}\left(300-650{ }^{\circ} \mathrm{C}\right)$ in the two samples is approximately 10 wt. \%. The wight loss in the low temperature range $(30-$ $250^{\circ} \mathrm{C}$ ) attributed to the physisorb water release is a litle lower for S13-18 (1.9 wt.\%) in respct to S24-5 (2.4 wt.\%).

Nitrogen adsorption-desorption analysis of S13-18 and S24-5 samples measured at $77 \mathrm{~K}$ showed Type I isotherms (Fig. 6a) with a sharp uptake at a low pressure of $\mathrm{P} / \mathrm{P}_{0}<0.05$, which is characteristic of microporous materials. The BrunauerEmmett-Teller (BET) equation was applied over the $0.05<$ $\mathrm{P} / \mathrm{PO}<0.25$ range of the isotherms. The micropore volume $\left(0.13 \mathrm{~cm}^{3} \mathrm{~g}^{-1}\right)$ of $\mathrm{S} 13-18$ are substantially higher in respect to S24-5 $\left(0.10 \mathrm{~cm}^{3} \mathrm{~g}^{-1}\right)$. We attribute the higher micropore volume to thehigher crystallinity of SSZ-13 seeded sample (Table 3 ).
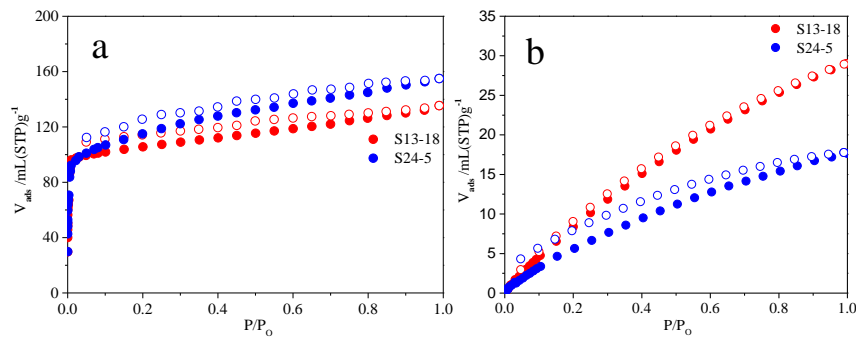

Fig. $6 \mathrm{~N}_{2}$ physisorption isotherms (a) and $\mathrm{CO}_{2}$ adsorption isotherms (b) of S13-18 and S24-5 samples at $77 \mathrm{~K}$ and $273 \mathrm{~K}$ respectively.

S13-18 showed also a substantially higher $\mathrm{CO}_{2}$ adsorption than S24-5 (Fig. 6b). According to the elemental analysis (Table 3), the $\mathrm{Si} / \mathrm{Al}$ ratio of S13-18 is 196 while S24-5 is 299 . Both zeolites are almost all-silica materials, and thus impact of the framework composition on the adsporption properties is not expected.

\begin{tabular}{lcclll}
\multicolumn{6}{l}{ Table 3 Comparison of physicochemical properties of S13-18 and S24-5 samples. } \\
\hline Samples & Seed (wt.\%) & Yield $/ \%$ & $S_{\text {BET }} / \mathrm{m}^{2} \mathrm{~g}^{-1}$ & $V_{\text {mic }} / \mathrm{cm}^{3} \mathrm{~g}^{-1}$ & $\mathrm{Si} / \mathrm{Al}$ \\
\hline S24-5 & 4.2 & 61 & 407 & 0.10 & 299 \\
S13-18 & 0.3 & 80 & 413 & 0.13 & 196 \\
\hline
\end{tabular}

\section{Conclusions}

In summary, we have developed a seed-assisted synthesis method for rapid crystallization of highly crystalline SSZ-24. The synthesis time was substantially shortened from 22 days in conventional synthesis to $22 \mathrm{~h}$ in our seeded system. This result was obtained with a catalytic amount (0.3 wt.\%) of seeds, which make the synthesis particularly attractive for practical use. The reduction of the crystallization time and seed content was achieved without compromising the crystallinity (>90\%) of the product. Thus the seed-assisted synthesis, with appropriate aging and selection of alkaline metal cations, directs the rapid crystallization of SSZ-24 and prevents the formation of undesired phase. This study illustrates that the seeded approach can properly address the crystallization of the most challenging zeolite.

\section{Conflicts of interest}

There are no conflicts to declare.

\section{Acknowledgements}

Q.F. and V.V. thank the National Natural Science Foundation of China (21571079, 21621001, 21390394, 21571076 and 21571078) for the financial support. Q.F and V.V. acknowledge the support from the Thousand Talents program (China).

\section{Notes and references}

1 C. Martínez and A. Corma, Coordin. Chem. Rev., 2011, 255, 1558-1580.

2 J. Gascon, F. Kapteijn, B. Zornoza, V. Sebastian, C. Casadoand and J. Coronas, Chem. Mater., 2012, 24, 2829-2844.

3 N. Kosinov, C. Auffret, V. G. Sripathi, C. Gücüyener, J. Gascon, F. Kapteijn and E. J. Hensen, Micropor. Mesopor. Mat., 2014, 197, 268-277.

4 M. Mofarahi and F. Gholipour, Micropor. Mesopor. Mat., 2014, 200, 1-10.

5 A. Primo and H. Garcia, Chem. Soc. Rev., 2014, 43, 75487561.

6 K. Li, J. Valla and J. Garcia-Martinez, ChemCatChem., 2014, 6, 46-66.

7 G.T. Kerr, J. Phys. Chem., 1966, 70, 1047-1050.

8 G.T. Kerr, J. Phys. Chem., 1968, 72, 1385-1386.

9 Y.V. Mirskii and VV. Pirozhko, Russ. J. Phys Chem., 1970, 44, 1508.

10 H. Kacirek and H. Lechert, J. Phys. Chem., 1975, 79, 15891593.

11 K. Iyoki, K. Itabashi and T. Okubo, Micropor. Mesopor. Mat., 2014, 189, 22-30.

12 L. Chen, T. Xue, H. Wu and P. Wu, RSC Advances., 2018, 8, 2751-2758.

13 C.S. Cundy and P.A. Cox, Chem. Rev., 2003, 103,663-701. 
14 H. Kacirek and H. Lechert, J. Phys. Chem., 1975, 79, 15891593.

15 C.S. Cundy, M.S. Henty and R.J. Plaisted, Zeolites., 1995, 5, 353-372.

16 J.P. Verduijn, World Patent 9308124, 1993.

17 C.S. Cundy, J.O. Forrest and R.J. Plaisted, Micropor. Mesopor.Mat., 2003, 66, 143-156.

18 J. Bronić, B. Subotić, M. Škreblin, Micropor. Mesopor. Mater., 1999, 28, 73-82.

19 Y. Kamimura, S. Tanahashi, K. Itabashi, A. Sugawara, T. Wakihara, A. Shimojima and T. Okubo, J. Phys. Chem. C., 2010, 115, 744-750.

20 Z. Liu, T. Wakihara, D. Nishioka, K. Oshima, T. Takewaki, and T. Okubo, Chem.Commun., 2014, 50, 2526-2528.

21 V. Valtchev, J. Mater. Chem., 2002, 12, 1914-1918.

22 Ch. Baerlocher, W.M. Meier and D.H. Olson, Atlas of Zeolite Framework Types, fifth ed., Elsevier, Amsterdam, 2001. http://www.iza-structure.org/databases/.

23 S.I. Zones, US Patent 4665110, 1989.

24 R. A. Van Nordstr, D. S. Santilli and S. I. Zones, ACS Symp. Ser.; Am. Chem. Soc., Washington, DC, 1988

25 R. Bialek, W. Meier, M. Davis and M. Annen, Zeolites., 1991, 11, 438-442.

26 A. J. M. De Man, W. P. J. H. Jacobs, J. P. Gilson and R. A. Van Santen, Zeolites., 1992, 12, 826-836.

27 S. I. Zones and Y. Nakagawa, Micropor. Mater., 1994, 2, 543555.

28 R. F. Lobo and M. E. Davis, Micropor. Mater., 1994, 3, 61-69.

29 H. Maekawa, Y. Kubota and Y. Sugi, Chem. Lett., 2004, 33 1126-1127.

30 Y. Kubota, H. Maekawa, S. Miyata, T. Tatsumi and Y. Sugi, Micropor. Mesopor. Mat., 2007, 101, 115-126.

31 V. Valtchev, J. L. Paillaud, H. Kessler and E. J. Creyghton, Micropor. Mesopor. Mat., 1999, 33, 143-148.

32 C. Peng, Z. Liu, T. Okubo and T. Wakihara, Chem. Lett., 2018, 47, 654-656.

33 L. Tang, K. G. Haw, Y. Zhang, Q. Fang, S. Qiu and V. Valtchev, Micropor. Mesopor. Mat., 2019, 280, 306-314.

34 D. Zhao, R. Szostak and L. Kevan, J. Mater. Chem., 1998, 8,233-239.

35 R. Aiello, F. Crea, E. Nigro, F. Testa, R. Mostowicz, A. Fonseca and J. B. Nagy, Micropor. Mesopor. Mat., 1999, 28, 241-259.

36 C. S. Gittleman, A. T. Bell, and C. J. Radke, Catal. Lett., 1996, 38, 1-9.

37 C. Liu, W. Gu, D. Kong and H. Guo, Micropor. Mesopor. Mat. 2014, 183, 30-36.

38 R. Aiello, F. Crea, F. Testa, G. Demortier, P. Lentz, M. Wiame and J. B. Nagy, Micropor. Mesopor. Mat., 2000, 35, 585-595. 